\title{
Dermite Flagelada a Cogumelos Shiitake
}

\section{Shiitake Mushroom-Induced Flagellate Erythema}

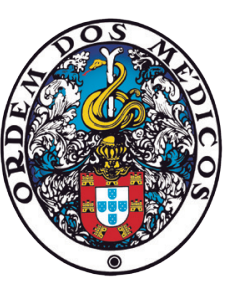

Alexandre MIROUX-CATARINO ${ }^{1}{ }^{1}$, Cristina CLARO

Acta Med Port 2021 Apr;34(4):304-304 - https://doi.org/10.20344/amp.12480

Palavras-chave: Cogumelos Shiitake; Eritema/etiologia; Intoxicação Alimentar por Cogumelos

Keywords: Erythema/etiology; Mushroom Poisoning; Shiitake Mushrooms

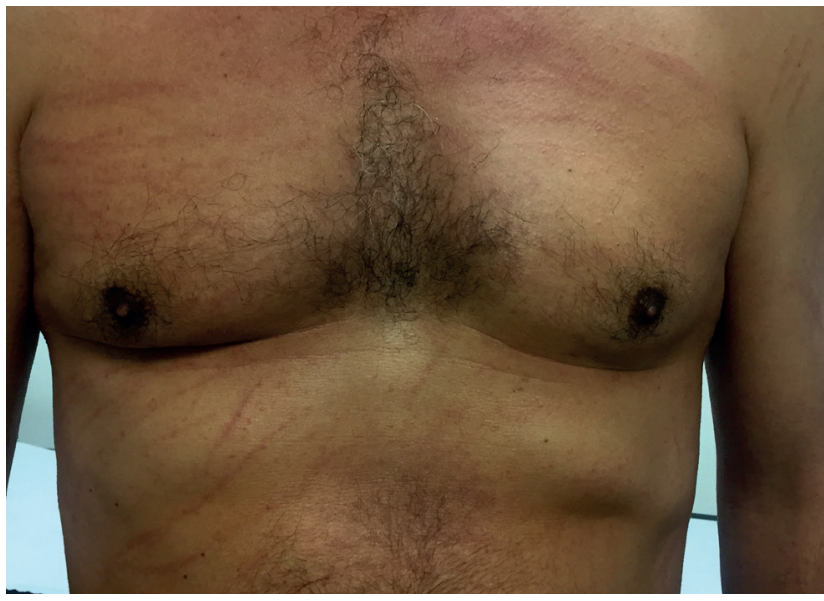

Figura 1 - Pápulas e placas eritematosas de distribuição linear na face anterior do tórax, abdómen e membros superiores

Doente do sexo masculino de 36 anos sem antecedentes relevantes ou medicação habitual, observado por pápulas eritematosas de distribuição linear localizadas no tronco e membros superiores com prurido associado, sem outras queixas (Fig.s 1 e 2). Apurou-se a ingestão de cogumelos shiitake mal cozidos dois dias antes do início do quadro. Dada a história e lesões típicas e a ausência de sintomatologia sistémica não foram realizados exames complementares de diagnóstico. Foi instituída terapêutica com anti-histamínico oral e corticoterapia tópica.

A dermite flagelada caracteriza-se por lesões eritematosas de distribuição linear que simulam flagelação. Além da ingestão de cogumelos shiitake crus ou mal cozidos, pode estar associada entre outros à terapêutica com bleomicina

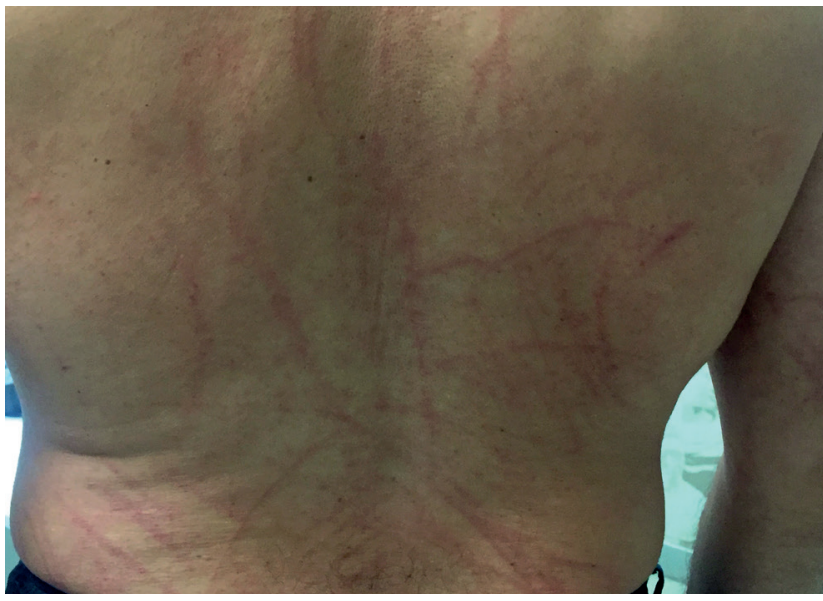

Figura 2 - Pápulas e placas eritematosas de distribuição linear no dorso e braço direito

ou à dermatomiosite. ${ }^{1} \mathrm{~A}$ associação com ingestão de cogumelos shiitake foi reportada pela primeira vez em 1977 por Nakamura. ${ }^{2} \mathrm{O}$ lentinan é o polissacárido termolábil responsável, que poderá atuar via secreção de interleucina-1 ou outras citocinas que levem a vasodilatação, a hemorragia e à erupção cutânea. ${ }^{3}$ Parece haver uma susceptibilidade individual à toxicidade cutânea. ${ }^{3} \mathrm{~A}$ dermatose surge dois a cinco dias após a ingestão, associa-se frequentemente a prurido e resolve espontaneamente em uma a três semanas, sem hiperpigmentação residual. ${ }^{4} \mathrm{O}$ lentinan é inativado pelo calor pelo que indivíduos afetados podem re-ingerir cogumelos shiitake desde que adequadamente cozinhados. ${ }^{5}$

PROTECÇÃO DE PESSOAS E ANIMAIS: Os autores declaram que os procedimentos seguidos estavam de acordo com os regulamentos estabelecidos pelos responsáveis da Comissão de Investigação Clínica e Ética e de acordo com a Declaração de Helsínquia da Associação Médica Mundial atualizada em 2013. CONFIDENCIALIDADE DOS DADOS: Os autores declaram ter seguido os protocolos do seu centro de trabalho acerca da publicação de dados. CONSENTIMENTO INFORMADO: Obtido. CONFLITOS DE INTERESSE: Os autores declaram não ter qualquer conflito de interesse relativamente ao presente artigo. FONTES DE FINANCIAMENTO: Sem fontes externas de financiamento para a realização deste artigo

\section{REFERÊNCIAS}

1. Adriano AR, Acosta ML, Azulay DR, Quiroz CD, Talarico SR. Shiitake dermatitis: the first case reported in Brazil. An Bras Dermatol. 2013;88:417-9.

2. Nakamura T. Toxicoderma caused by shiitake (Lentinus edodes). Jpn J Clin Dermatol. 1977;31:65-8.

3. Mendonça CN, Silva PM, Avelleira JC, Nishimori FS, Cassia Fd. Shiitake dermatitis. An Bras Dermatol. 2015;90:276-8.

4. Wang AS, Barr KL, Jagdeo J. Shiitake mushroom-induced flagellate erythema: a striking case and review of the literature. Dermatol Online J. 2013;19:5.

5. Karanovic S, George S, Topham E. Don't miss shiitake dermatitis: a case report. Br J Gen Pract. 2014;64:426-7.

\footnotetext{
1. Serviço de Dermatologia. Hospital Egas Moniz. Centro Hospitalar Lisboa Ocidental. Lisboa. Portugal.

$\triangle$ Autor correspondente: Alexandre Miroux-Catarino. alexandre catarino@hotmail.com

Recebido: 25 de junho de 2019 - Aceite: 18 de novembro de 2019 - Online issue published: 01 de abril de 2021

Copyright $\odot$ Ordem dos Médicos 2021
} 